\title{
Biomass Equations for Castanea sativa High Forest in the Northwest of Portugal
}

M.S. Patrício and M.L. Monteiro

Department of Forestry

Polytechnic Institute of Bragança-ESAB

Quinta Sta. Apolónia, Apartado 172

5301-855 Bragança

Portugal

\author{
M. Tomé \\ Department of Forestry, ISA \\ Tapada da Ajuda \\ 1349-017 Lisboa \\ Portugal
}

Keywords: sweet chestnut, aboveground biomass, allometric models

\begin{abstract}
There is considerable interest today in estimating the biomass of trees and forests for practical forestry issues, sustainable management, carbon and nutrient flux and other scientific purposes. For these reasons, aboveground biomass was studied in Castanea sativa high forest stands located in the Northwest of Portugal. The most widely used procedure for stand biomass evaluation is the regression estimation method, in which the stand biomass is predicted through the sum of the predicted biomass of individual trees. In this study, thirty-four old sweet chestnut trees, located in three stands, were felled, measured and weighted to evaluate the aboveground biomass by components. Several linear and nonlinear equations were fitted by the least squares method to select a model that predicts total tree aboveground biomass as well as bole-wood, bole-bark, branches, leaves and flowers biomass components as a function of DBH (diameter at breast height) and total height. For each component the model that fit better was selected.
\end{abstract}

\section{INTRODUCTION}

The biomass and nutrient relationships are essential for the studies of ecosystem dynamics and its functionality. The knowledge of the contents of the mineral elements in the several components of the trees is essential to understand its state and flow in the globality of the system, as well as to evaluate the site sustainability. It is also important for commercial uses (e.g., fuel and fibre) and for national development planning, as well as for scientific studies of ecosystem productivity, energy and nutrient flows, and for assessing the contribution of changes in forestlands to the global carbon cycle (Parresol, 1999).

Moreover, these equations can be used to predict the growth of young stands (Wagner and Ter-Mikaelin, 1999), and to be a part of production models, in order to model forest growth at both tree and stand levels (Korzukhin, 1996), in order to analyse the long term productivity and the site sustainability, as well as to foresee the potential carbon sequestering of the stands (Reed et al., 1995).

The information concerning the individual tree biomass can be used in large forest inventories and to solve a great variety of ecological and forest problems, allowing to relate, for example, the amount of fuel with the fires propagation conditions, and to evaluate the residues resulting from forest activities not only at an economic level, but also in terms of loss or gain for the ecosystem.

Concerning the Kyoto Protocol, it is important to determine sources and sinks of carbon resulting from land-use change (and, perhaps, from natural processes as well), and also methods that can determine biomass accurately, reportedly, and inexpensively are desperately needed (Houghton et al., 2001).

The allometric equations are today broadly used to estimate forest biomass. In spite of that very little information concerning chestnut, some authors have obtained valuable results concerning the coppice stands (Gallego et al., 1994; Leonardi et al., 1996a). Biomass and nutrient studies on sweet chestnut, concerning some of its components (particularly the litter), were carried out by Ranger et al. (1990), Leonardi et 
al. (1996b), Martin et al. (1996), Regina (2000), Regina et al. (2001), and Martins et al. (1999) for coppiced stands and Pires et al. (1996) for chestnut groves.

Thus, given the importance of the biomass relationships for the analysis of productivity, dynamics and sustainable functioning of chestnut ecosystems, the purpose of this work was to develop equations to predict tree biomass per plant component as a function of tree biometric variables to be applied to this species in high forest management.

\section{MATERIALS AND METHODS}

\section{Data}

In order to obtain biomass data, 34 trees were felled according to the existent diameter classes. Three selected, mature chestnut high forest stands located in the North

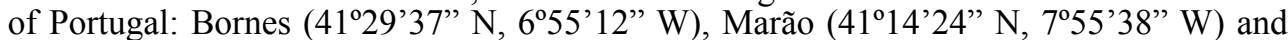
Padrela (4130'34" N, 7³6'54" W) were studied.

The trees were randomly selected in each stand: 18 trees in Padrela, 7 trees in Bornes, and 9 trees in Marão, distributed by the diameter classes, according to its frequency. The study was carried out during the vegetative period, when the leaves already presented its maximum dimension.

The total length of the tree and the height to the base of the living crown were measured, the last corresponding to the first living branch considered significant (Liu and Burkhart, 1993), in this case only if the diameter was greater than $2.5 \mathrm{~cm}$. The main stem was sectioned with the first cut at breast height level previously marked in the tree. Starting from this level the stems were sectioned in $2.25 \mathrm{~m}$ logs until the diameter of 7 $\mathrm{cm}$. In the inferior section of each $\log$ a disk with $5 \mathrm{~cm}$ of thickness was kept for biomass analysis. The fresh weight for the following tree components [leaves, flowers, branches, logs 1 to $\mathrm{n}$ (W1....Wn) with bark, disks ( 1 to $\mathrm{n}$ ) with bark and bark of the disks 1 to $\mathrm{n}$ ] was obtained in situ. One kilo of sample of each component was obtained randomly for laboratory determination. These samples were put into hermetic polyethylene bags, appropriately identified and weighed, and kept in portable chilly bins.

\section{Treatment of the Samples in Laboratory}

Samples of leaves, flowers and barks were dried in a stove at $70 \pm 2^{\circ} \mathrm{C}$, while the $\log$ samples and branches, were dried at $103 \pm 2^{\circ} \mathrm{C}$ (until constant weight) for determining the natural humidity and estimating the dry matter.

The set of data used in biomass modelling is characterised in Table 1.

\section{Data Analysis}

To model the biomass $(W)$ by components, the following candidate allometric functions were tested for each tree component:

(1) $w=\beta_{1}(D B H)^{2} h$

(2) $w=\beta_{1}\left((D B H)^{2} h\right)^{\beta 2}$

(3) $w=(D B H)^{2} /\left(\beta_{1}+\beta_{2} h^{-1}\right)$

(4) $w=\beta_{0}+\beta_{1}(D B H)^{\beta 2} h^{\beta 3}$

(5) $w=\beta_{1}(D B H)^{\beta 2} h^{\beta 3}$

(6) $w=\beta_{1}(D B H)^{\beta 2}$

(7) $w=\beta_{1}(D B H)^{\beta 2} e^{(\beta 3(D B H))}$

(8) $w=\beta_{0}+\beta_{1}(D B H)^{2} h$

(9) $w=(D B H)^{(\beta O+\beta 1 h c)}$

In a first phase, the functions were tested for each of the plant components. Due to the low correlation initially found between the biomass of some of the components considered and the tree variables [diameter breast height (DBH), crown base diameter (dbc), total height (h), height to the base of the living crown (hbc) and length of the crown 
(hc)], the dry matter of some components considered separately during the phase of data collection was pooled. Thus, both the flowers and the leaves were joint together in the same category designated as (W_Ltot). The biomass of the living branches was also pooled in another category, named (W_Bliv). Apart from these, the following categories were considered for analytical purposes: bark biomass (W_Bark), main stem under bark biomass (W_Wood), main stem over bark biomass (W_Bole), and the total aboveground biomass ( $\mathrm{W}^{-}$Tot).

The biomass equations were fitted by the ordinary least squares method (OLS) associated with both the PROC REG (linear models) and PROC NLIN (non linear models) procedures of SAS/STAT. The modified Gauss-Newton iterative method was applied in the non linear model fitting.

The models were evaluated in terms of measures of fit and prediction ability: modelling efficiency (EM), mean square error (MSE), models parameter significance, $\mathrm{R}^{2}$ of prediction (R2pred), mean of PRESS residuals (m_PRESS), and mean of the absolute values of the PRESS residuals (ma PRESS) as well as the percentiles 95\% (P95) and 5\% (P5) of the PRESS residuals. The normality of the studentized residuals was analysed using normal QQplots. The presence of heterocedasticity associated with the error term of the models was checked by plotting the studentized residuals against the predicted values.

The lack of homogeneity in the variation of the residuals is a typical feature of the biomass data referred to by several authors. The regression assumptions departure was solved with non linear iteratively rewheighted least squares (IRWLS) using the Huber function with the maximum value of $\mathrm{r}=1$ and weighting factors.

Most of the models were immediately eliminated because they led to nonsignificant parameters.

\section{RESULTS AND DISCUSSION}

The models already presented were fitted to the biomass data as described in the methodology. Obtained data were exposed on tables. Among the considered independent variables, the crown base diameter $(d b c)$ and the correspondent height $(h b c)$ did not present a superior contribution for the model error explanation relatively to the diameter at breast height $(D B H)$ and the total height $(h)$. This fact, associated to the easiness of variables mensuration, important for a future use of the models, leads to considering mainly the variables (DBH) and $(h)$ as final regressor variables.

Table 2 presents fitting, precision and bias statistics for the selected models. The plot analysis of the studentised residuals was also taken into consideration, as well as the advantages of using or not the less practical independent variables, related to the crown. In order to sort out the models, a scale we organised for each parameter considered, and the models classified according to the sum of the given values, with the one showing a lower as the first one. Simplifying, only the models with all significant parameters, after weighting, were considered.

The analysis accomplished, based on the criteria previously mentioned, led to the selection of the following models for each tree component:

(2) $W_{-}$Barc $=0.0141\left((\mathrm{DBH})^{2} h\right)^{0.7892}$

(3) $W_{-}$Ltot $=(\mathrm{DBH})^{2} /\left(187.7-1791.6 \mathrm{~h}^{-1}\right)$

$E M=0.9655$

(1) $W$ Bliv $=0.00451(\mathrm{DBH})^{2} h$

(5) $W$ Wood $=0.0160 \mathrm{DBH} u b^{1,7308} h^{1.3088}$

$E M=0.7887$

$E M=0.7724$

(5) $W^{-}$Bole $=0.0142 \mathrm{DBH}^{1, \overline{7} 243} h^{1.3582}$

$E M=0.9882$

$E M=0.9869$

(6) $W_{-}$tot $=0.1236 \mathrm{DBH}^{2,3929}$

$E M=0.9883$

These equations predict the biomass of the different components in $\mathrm{kg}$, based on the diameter at $1.30 \mathrm{~m}(\mathrm{DBH})$ in $\mathrm{cm}$ (with bark, except for the wood biomass $D B H \_u b$ ) and the total height $(h)$ in $\mathrm{m}$.

The selected equations were used to estimate the total biomass and biomass by components of the individual trees in the three studied stands. 
Aboveground biomass for the three stands, total biomass and biomass by tree component are presented in Table 3 . The Padrela stand is the oldest one (65 years old), showing trees of the higher diameter classes, when compared to the other two populations. In spite of this, it shows a total biomass and a biomass by components considerably lower than others, because of its lower density.

The contribution in percentage of each plant component for the total biomass is not very different among the three stands. Bornes site presents a higher percentage of bark, because it has a smaller amount of wood distributed throughout a larger number of small trees.

\section{CONCLUSIONS}

The wood biomass prevails not only at the stem level, contributing with more than $70 \%$ of the aboveground biomass. The branches are responsible for about $20 \%$, followed by the bark, with approximately $7 \%$ of the total and the leaves and flowers with only $1.5 \%$, approximately. Thus, $78.5 \%$ to $80 \%$ of the chestnut high forest aboveground total biomass comes from the main stem, whereas $20 \%$ to $21.5 \%$ results from the crown.

The information obtained with these biomass equations, applicable to data of individual trees, can be applied to the forest inventories as well as to a great variety of ecological problems, like fire studies, allowing to relate the amount of fuel with the fires propagation conditions, the carbon sequestering, the site sustainability and similar studies.

\section{ACKNOWLEDGMENTS}

This work was supported by the AGRO Program, Project 267: Sustainable Management of Chestnut Forested Areas in High Forest and Coppice Systems.

\section{Literature Cited}

Gallego, H.A., Rico, M. and Regina, I.S. 1994. Biomass equations and nutrient content for a Castanea sativa Mill. Forest. In: Proc. Intl. Congress on Chestnut, Spoleto, Italy, 1993.

Houghton, R.A., Lawrence, K.T., Hackler, J.L. and Brown, S. 2001. The spatial distribution of forest biomass in the Brazilian Amazon: a comparison of estimates. Global Change Biology 7:731-746.

Korzukhin, M.D., Ter-Mikaelian, M.T. and Wagner, R.G. 1996. Process versus empirical models: which approach for forest ecosystem management? Can. J. For. Res. 26:879887.

Leonardi, S., Regina, I.S., Rapp, M., Gallego, H.A. and Rico, M. 1996a. Biomass, litterfall and nutrient content in Castanea sativa coppice stands of southern Europe. Ann. Sci. For. 53:1071-1081.

Leonardi, S., Rapp, M., Gallego, H.A., Failla, M. and Guarnaccia, D. 1996b. Biomasse, productivité et transferís de matière organique dans une séquence altitudinale de peuplements de Castanea sativa Mill de 1’Etna. Ann. Sc. For. 53:1031-1048.

Liu, J. and Burkhart, E.H. 1993. Dynamics of size-variable distribution parameters in juvenile loblolly pine (Pinus taeda L.) stands. For. Ecol. Man. 58:321-347.

Martin, A., Gallardo, J.F. and Regina, I.S. 1996. Dinámica de las fracciones orgánicas en la descomposicion de hojas de rebollos castanho. Silv. Lus. 4(2):199-216.

Martins, A., Azevedo, S. and Carvalho, L. 1999. Dynamics of leaf litter structural compounds in $C$. sativa and $P$. pinaster forest ecosystems during the decomposition process: interactions with soil organic matter and nutrient release. Acta Hort. 494:161166.

Parresol, B.R. 1999. Assessing tree and Stand Biomass: a review with examples and critical comparations. For. Sci. 45(4):573-593.

Pires, A.L., Ribeiro, E., Correia, I., Barroso, N., Claudino, F. and Portela, E. 1999. Effect of ink disease on chestnut litterfall production and on nutrient budgets over a 3-year period. Acta Hort. 494:149-154.

Ranger, J., Félix, C., Bouchon, J., Nys, C. and Ravart, M. 1990. Dynamique d'incorpora- 
tion du carbone et des éléments nutritifs dans un taillis simple de châtaigner (Castanea sativa). Ann. Sci. For. 47:413-433.

Reed, D.D., Mroz, G.D., Liechty, H.O., Jones, E.A., Cattelino, P.J., Balster, N.J. and Zhang, Y. 1995. Above and below-ground biomass of precompetitive red pine in Northern Michigan. Can. J. For. Res. 25:1064-1069.

Regina, I.S. 2000. Organic matter distribution and nutrient fluxes within a sweet chestnut (Castanea sativa Mill.) stand of the Sierra de Gata, Spain. Ann. For. Sci. 57:691-700.

Regina, I.S., Leonardi, S. and Rapp, M. 2001. Foliar nutrient dynamics and nutrient-use efficiency in Castanea sativa coppice stands of southern Europe. Forestry 74(1):1-10.

Wagner, R.G. and Ter-Mikaelian, M.T. 1999. Comparison of biomass component equations for four species of northern coniferous tree seedlings. Ann. For. Sci. 56:193199.

\section{Tables}

Table 1. Characterisation of the data set used in the biomass modelling.

\begin{tabular}{lrcrc}
\hline \multirow{2}{*}{ Component } & \multicolumn{4}{c}{ Aboveground biomass of trees $(\mathrm{kg})(\mathrm{n}=34)$} \\
\cline { 2 - 5 } & Min. & Average & Max. & Stand. deviation \\
\hline W_Wood & 21.10 & 472.22 & 1416.15 & 381.01 \\
W_Bark & 4.83 & 48.81 & 134.08 & 34.79 \\
W_Flower & 0.05 & 2.02 & 13.83 & 3.08 \\
W_Lives & 0.85 & 10.45 & 43.41 & 8.80 \\
W_Blive & 3.91 & 153.05 & 735.97 & 190.66 \\
W_Bdead & 0.43 & 49.60 & 725.79 & 131.07 \\
W_Btot & 3.91 & 198.27 & 1461.83 & 287.19 \\
W_Tot & 34.87 & 731.64 & 2658.83 & 648.62 \\
\hline \multirow{2}{*}{ Variable } & \multicolumn{4}{c}{} \\
\cline { 2 - 5 } & Min. & Biometric variables of trees (n=34) & \\
\hline DBH (cm) & 10.25 & 33.98 & 64.20 & Stand. deviation \\
h (m) & 11.55 & 21.91 & 30.40 & 14.14 \\
dbc (cm) & 8.55 & 26.81 & 62.00 & 4.63 \\
hbc (m) & 2.19 & 9.28 & 19.36 & 13.18 \\
\hline
\end{tabular}

W_Wood: biomass of the stem without bark; W_Bark: bark biomass; W_Flower: flowers biomass; W_lives: lives biomass; W Blive: live branches biomass; W Bdead: dead branches biomass. W Btot: live and dead branches biomass; W_Tot: total biomass; dbc: crown base diameter; hbc: crown height; $\mathrm{h}$ : total height; DBH: diameter breast height. 
Table 2. Fitting and prediction statistics for the biomass models with the best performance, after the IRWLS.

\begin{tabular}{ccccccccr}
\hline Mod. & Comp. & MSE & EM & mPRESS & maPRESS & $\mathrm{R}_{\text {pred }}^{2}$ & P95 & P5 \\
\hline (2) W_Bark & 0.0271 & 0.9655 & 0.2605 & 5.5818 & 0.9518 & 15.4379 & -15.2183 \\
(3) W_Ftot & 0.8062 & 0.7887 & -0.0180 & 3.8283 & 0.7299 & 10.3780 & -5.7564 \\
(1) W_Bliv & 4.1846 & 0.7724 & 5.5598 & 77.8096 & 0.5483 & 340.4550 & -152.2570 \\
(5) W_Wood & 26.8100 & 0.9882 & -0.9964 & 42.4307 & 0.9642 & 127.1610 & -65.4566 \\
(5) W_Bol & 33.6004 & 0.9869 & -2.0055 & 49.0936 & 0.9599 & 138.3160 & -72.2298 \\
(6) W_Tot & 2.9359 & 0.9883 & 1.2531 & 60.4847 & 0.9827 & 124.1600 & -149.8300 \\
\hline
\end{tabular}

The model (1) was fitted linearly, with the same weighting factor as used in the others. EM: modelling efficiency; P95: percentile 95; P5: percentile 5; mPRESS and maPRESS: mean and absolute mean of PRESS residuals, respectively; MSE: mean square error.

Table 3. Total aboveground biomass and biomass by plant component for the populations studied.

\begin{tabular}{lrrrrrr}
\hline \multirow{3}{*}{ Component } & \multicolumn{4}{c}{ Estimated aboveground biomass by site } \\
\cline { 2 - 7 } & \multicolumn{2}{c}{ Bornes } & \multicolumn{2}{c}{ Marão } & \multicolumn{2}{c}{ Padrela } \\
& \multicolumn{2}{c}{$\left(1227\right.$ trees ha $\left.^{-1}\right)$} & \multicolumn{2}{c}{$\left(485\right.$ trees ha $\left.^{-1}\right)$} & \multicolumn{2}{c}{$\left(259\right.$ trees ha $\left.^{-1}\right)$} \\
\cline { 2 - 7 } & $\mathrm{Mg} \mathrm{ha}^{-1}$ & \multicolumn{1}{c}{$\%$} & $\mathrm{Mg} \mathrm{ha}^{-1}$ & $\%$ & $\mathrm{Mg} \mathrm{ha}^{-1}$ & $\%$ \\
\hline Wood & 294.1 & 72.5 & 328.0 & 71.7 & 152.4 & 713 \\
Bark & 30.8 & 7.6 & 31.7 & 6.9 & 15.6 & 7.3 \\
Branches & 75.2 & 18.5 & 90.9 & 19.9 & 42.5 & 19.9 \\
Leaves + Flowers & 5.7 & 1.4 & 6.9 & 1.5 & 3.2 & 1.5 \\
Total & 405.8 & 100 & 457.5 & 100 & 213.7 & 100 \\
\hline
\end{tabular}

